Marquette University

e-Publications@Marquette

Mathematics, Statistics and Computer Science Mathematics, Statistics and Computer Science, Faculty Research and Publications

9-2013

\title{
An Investigation of Teachers' Intentions and Reflections About Using Standards-Based and Traditional Textbooks in the Classroom
}

\author{
Bikai Nie \\ University of Delaware \\ Tony Freedman \\ University of Delaware \\ Stephen Hwang \\ University of Delaware \\ Ning Wang \\ Widener University - Main Campus \\ John Moyer \\ Marquette University, john.moyer@marquette.edu
}

See next page for additional authors

Follow this and additional works at: https://epublications.marquette.edu/mscs_fac

Part of the Computer Sciences Commons, Mathematics Commons, and the Statistics and Probability Commons

\section{Recommended Citation}

Nie, Bikai; Freedman, Tony; Hwang, Stephen; Wang, Ning; Moyer, John; and Cai, Jinfa, "An Investigation of Teachers' Intentions and Reflections About Using Standards-Based and Traditional Textbooks in the Classroom" (2013). Mathematics, Statistics and Computer Science Faculty Research and Publications. 123.

https://epublications.marquette.edu/mscs_fac/123 
Authors

Bikai Nie, Tony Freedman, Stephen Hwang, Ning Wang, John Moyer, and Jinfa Cai

This article is available at e-Publications@Marquette: https://epublications.marquette.edu/mscs_fac/123 
Marquette University

e-Publications@Marquette

\section{Mathematics and Statistical Sciences Faculty Research and Publications/College of Arts and Sciences}

This paper is NOT THE PUBLISHED VERSION; but the author's final, peer-reviewed manuscript. The published version may be accessed by following the link in the citation below.

ZDM Mathematics Education, Vol. 45 (September 2013): 699-711. DOI. This article is (C) Springer and permission has been granted for this version to appear in e-Publications@Marquette. Springer does not grant permission for this article to be further copied/distributed or hosted elsewhere without the express permission from Springer.

\section{An Investigation of Teachers' Intentions and Reflections About Using Standards-Based and Traditional Textbooks in The Classroom}

Bikai Nie

University of Delaware, 523 Ewing Hall, Newark, DE

Tony Freedman

University of Delaware, 523 Ewing Hall, Newark, DE

Stephen Hwang

University of Delaware, 523 Ewing Hall, Newark, DE

Ning Wang

Widener University, Chester

John C. Moyer

Marquette University, Milwaukee, WI

Jinfa Cai

University of Delaware, 523 Ewing Hall, Newark, DE 


\section{Abstract}

This study analyzed teachers' intentions for and reflections on their use of Standards-based [Connected Mathematics Program (CMP)] textbooks and traditional (non-CMP) mathematics textbooks to guide instruction. In this investigation of the interplay between textbooks and instruction, we focused on learning goals, instructional tasks, teachers' anticipation of students' difficulties, and their perceptions of students' achievement of learning goals. All of these are aspects of teachers' intentions and reflections that have proved fruitful in comparing the roles of the CMP and non-CMP mathematics textbooks in our Longitudinal Investigation of the Effect of Curriculum on Algebra Learning project. Whereas the cognitive level of the teachers' intended learning goals appeared generally to reflect the emphases of their respective textbooks, we found that the CMP teachers' intended learning goals were not as well aligned with the CMP textbooks as the non-CMP teachers' learning goals were aligned with their non-CMP textbooks. The CMP and non-CMP teachers' implementations of the lessons seemed to reduce the degree of difference between the cognitive levels of their intended goals. Even so, we found that significantly more CMP lessons than non-CMP lessons were implemented at a high level of cognitive demand. Although the non-CMP teachers' intended learning goals were better aligned with their textbook's learning goals, we found that the CMP teachers were more likely than the non-CMP teachers to follow the guidance of their textbooks in designing and selecting instructional tasks for a lesson. Future research should consider other aspects of teachers' intentions and reflections that may shed a broader light on the role of textbooks and curriculum materials in teachers' crafting of instructional experiences for their students.

\section{Introduction}

In the United States, textbooks and curriculum materials based on the NCTM Standards have been implemented for more than a decade. Yet, debate about the effectiveness of these curricula continues (Cai, $\mathrm{Ni}, \&$ Lester, 2011). A significant issue that has arisen in the debate concerns how these textbooks and curriculum materials actually influence the way teachers teach. Because the implementation of Standards-based curricula requires a fundamental change in the way that mathematics traditionally has been taught, teachers face daunting challenges when they try to use these curricula. The pull of tradition is so strong that even in classrooms where teachers are seriously attempting to teach in ways aligned with the NCTM Standards, teachers often maintain many existing mathematics practices inconsistent with reform (Gross \& Merchlinsky, 2002; Hiebert \& Stigler, 2000; RAND Mathematics Study Panel, 2003; Spillane \& Zeuli, 1999). Given this challenge, it has become clear that studies of the efficacy of Standards-based textbooks and curriculum materials must necessarily investigate the ways that teachers think about and transform these resources into instructional experiences for their students.

The study presented in this paper is part of a larger project, titled "Longitudinal Investigation of the Effect of Curriculum on Algebra Learning" (LieCal Project). The LieCal Project is designed to longitudinally compare the effects of the Connected Mathematics Program (CMP) to the effects of more traditional middle school curricula (hereafter called non-CMP curricula) on students' learning of algebra (Cai, Wang, Moyer, Wang, \& Nie, 2011; Moyer, Cai, Wang, \& Nie, 2011). One of the purposes of the LieCal Project is to provide a profile of classroom experiences that CMP students and teachers have, and contrast this with a profile of experiences in non-CMP classrooms.

In the past, we have examined the following three aspects of instruction, as they are experienced by students and teachers when using CMP and non-CMP curricula: (1) lesson structure and the use of materials (Cai, Nie, \& Moyer, 2010), (2) instructional tasks (Cai, Moyer, Nie, \& Wang, 2009), and (3) the nature and quality of instruction (Moyer, Cai, Laughlin, \& Wang, 2009). The purpose of the study reported in this paper is to examine how textbooks and curriculum materials influence classroom instruction through the lens of teachers' intentions and reflections related to their classroom instruction. Indeed, teachers' intentions for and reflections on 
classroom instruction have been identified as important elements of teaching that affect student learning (e.g., Butts, Koballa, Anderson, \& Butts, 1993; Hatton \& Smith, 1995). Here, we use these intentions and reflections to provide a perspective on how teachers' instruction is shaped by the texts and curriculum materials they use. In particular, the study reported here is focused on answering the following research questions:

1. What intentions do the CMP and non-CMP teachers' express regarding learning goals and potential difficulties as they shape and prepare to implement lessons from their respective curriculum materials?

2. What are the CMP and non-CMP teachers' reflections on the lessons they teach from their respective curriculum materials, including their perceptions of students' achievement of learning goals?

These intentions and reflections, combined with observations of teaching, provide a useful perspective on teachers' use of CMP and non-CMP textbooks and curriculum materials in their instruction.

\section{Background}

Classroom instruction is complex and difficult to measure (Jackson, 1990). To understand instructional processes, different researchers have focused on various aspects, such as teachers' knowledge and beliefs (e.g., Cooney, Shealy, \& Arvold, 1998; Fennema \& Franke, 1992; Thompson, 1992), instructional tasks (Cai \& Lester, 2005; Doyle, 1983, 1988; Hiebert \& Wearne, 1993; Stein, Grover, \& Henningsen, 1996), classroom discourse (e.g., Cazden, 1986; Lampert, 1990; Perry, VanderStoep, \& Yu, 1993), or student social interactions (e.g., Cobb \& Bauersfeld, 1995; Forman \& Cazden, 1985). In particular, Bolhuis (2003) pointed out that teaching consists of four central components that lead to student learning: (1) goal setting/orientation, (2) execution of learning activities, (3) evaluation, and (4) regulation and monitoring. Within these four components that shape the nature of teaching, "a key contextual variable" is the set of learning goals (Hiebert et al., 1997). Different curricula and textbooks can present very different sets of learning goals, even when they are nominally addressing the same mathematical topic. Therefore, in this study, we first focused on the intended and implemented learning goals for each lesson in order to see how the teachers interpreted the learning goals in their curricular materials and embodied them in classroom instruction.

We looked at several ways learning goals have been analyzed in previous studies, integrating elements from each into our analysis. Hiebert et al. (2003) classified the learning goals of the videotaped lessons for the TIMSS studies into three types: content goals, process goals, and perspective goals. These three types of goals relate to students' mathematics knowledge, students' ideas, and students' interest in mathematics, respectively. Some examples of process goals from Hiebert et al. are "solve equations," "solve problems," and "apply mathematics to everyday situations." When analyzing these types of process goals, Hiebert et al. did not differentiate between levels of cognitive demand. Fernandez and Cannon (2005) classified the goals of lessons taught by U.S. teachers and Japanese teachers into mathematical goals and proposition goals. Moreover, they coded the mathematical goals as conceptual or procedural. We did not think these codes were specific enough for the analysis of our data.

Anderson and Krathwohl (2001) modified Bloom's taxonomy of educational objectives to define six levels of cognitive demand that learning goals can encompass: remembering, understanding, applying, analyzing, evaluating, and creating by developing. Our data coding drew on Anderson and Krathwohl because the model aligned well with the way we analyzed both textbook and instructional tasks in our previous studies (e.g., Cai et al., 2009; Cai et al., 2010; Nie, Cai, \& Moyer, 2009).

A number of studies have focused on the influence of curriculum materials on teachers' instruction (e.g., Remillard, 2005; Spillane, 2000). Remillard (2005) has characterized the relationship between teachers and curriculum as a participatory relationship that is influenced both by teacher characteristics (including the 
teachers' learning goals and the teachers' perceptions of their students' abilities) and by curriculum characteristics (including the textbook's representations of tasks). With respect to classroom instruction, the tasks and activities provided by textbooks and curriculum materials form the instructional core for teachers and students in mathematics classrooms (Silver, Ghousseini, Charalambous, \& Mills, 2012). Students' learning is therefore highly related to the instructional tasks that teachers select and enact from their materials (Cai et al., 2009; Stein \& Lane, 1996). Moreover, many mathematics educators (e.g., Moyer, Cai, \& Laughlin, 2009; Stein and Smith, 1998; West \& Staub, 2003) have posited that mathematics tasks can serve as a productive framework for teachers' reflection. Consequently, to understand teachers' intentions for their classroom instruction better, we decided in this study to examine the tasks teachers chose to implement and their reasons for making those choices.

Finally, it has been well documented that teachers' knowledge of students' mathematical thinking is critical for improving students' learning (Carpenter, Fennema, Peterson, Chiang, \& Loef, 1989; Hill, Ball, \& Schilling, 2008; Shulman, 1986). When planning instruction with their curriculum materials, teachers must take into account what they know about their students' knowledge in order to tailor textbook lessons to their particular needs. In particular, teachers may need to adjust tasks or prepare responses in anticipation of difficulties their students may encounter. Indeed, in analyses of teaching in high-performing countries, teachers have noted that they take into account both their textbooks and their understanding of their students' cognition when planning their instruction (Cai \& Wang, 2010). In other words, it is not enough for teachers just to consider how they will present mathematical ideas; rather, teachers need to anticipate their students' perspectives, thinking and approaches (McDuffie \& Mather, 2012). Thus, as we examined teachers' intentions for and reflections on their lessons, we sought to determine whether the teachers anticipated any difficulties that their students might have with the mathematics in those tasks.

In summary, we focus on the following three dimensions to examine teachers' intentions for their mathematical lessons and their reflections on them: (1) learning goals, (2) the rationale for the instructional tasks used, and (3) anticipated student difficulties with the mathematics of the lessons. Because this study is situated in a comparative curricular context, we examine how different types of curricula may be related to teachers' intentions and reflections.

\section{Methods}

\section{Sample}

The LieCal Project was conducted in 14 middle schools of an urban school district serving a diverse student population. When the project began, 27 of the 51 middle schools in the district had adopted the CMP curriculum, and the remaining 24 had adopted more traditional curricula. Seven schools were randomly selected from the 27 schools that had adopted the CMP curriculum. After the seven CMP schools were selected, seven non-CMP schools were chosen based on comparable demographics. In sixth grade, 695 CMP students in 25 classes and 589 non-CMP students in 22 classes participated in the study (see Cai et al., 2011, for details about the research setting and the sample).

\section{Data collection}

We followed the LieCal teachers and students for 3 years, conducting classroom observations and interviews with teachers before and after the observations in order to document the middle school mathematics classroom instruction that the students received using the CMP and non-CMP curricula. Two highly qualified retired mathematics supervisors conducted all the interviews and observations. The observers received extensive training that included frequent checks for reliability and validity throughout the 3 years. Each LieCal class was observed four times per year, during two consecutive lessons in the fall and two in the spring. In total, we 
observed 305 CMP lessons taught by 30 teachers in 7 schools and 274 non-CMP lessons taught by 24 teachers in 7 schools. The interviews were conducted using 12 specific questions, 7 of which were designed for the beforelesson interview and 5 for the after-lesson interview (see Appendix A). Thus, the data for this study came from 579 classroom observations, 579 before-lesson interviews and 579 after-lesson interviews. It should be indicated that due to missing data, the actual sample sizes for our various statistical analyses varied and could be $<579$.

During each lesson, the observer made a minute-by-minute record of the classroom activities using an extensive 28-page LieCal Project-developed observation instrument. Afterwards, the observer coded the minute-byminute record of the lessons' activities into data about the structure of the lesson, the use of materials, and the nature of the instruction. Based on data from the observation of the lesson, the observer deduced what the implemented learning goals of the lesson were and whether those goals were consistent with the intended goals as specified in the textbook and curriculum materials (see Appendix B). In other words, the observer was asked to identify the primary learning goals or objectives of the observed lesson based on his/her own perceptions as an observer, not the perspective of the textbook or the interview responses from the teacher. The observer also identified the learning goals specified in the textbook and curriculum materials for each lesson. For the non-CMP lessons, the coders included all the objectives that were listed for the section being covered since each lesson was meant to cover an entire section of the book. However, for the CMP materials, it was necessary to determine which of the listed objectives were being addressed in a particular lesson since each section of the book was meant to be covered over a series of lessons.

Prior to the lesson, the observer interviewed the teacher to probe his or her intentions for the impending classroom instruction and to find out any background information related to the day's lesson (see Appendix A). The observer asked the teacher about the topic of the lesson, whether he or she had taught the lesson before, and to identify the primary learning goals or objectives in the lesson. In addition, the teachers were asked to situate the lesson in the unit they were teaching and to comment on potential difficulties they anticipated (either student difficulties with the mathematics or difficulties delivering the lesson). Finally, the observer asked about the teachers' plans for later student assessment.

After the observation, the observer again interviewed the teacher to probe the teacher's reflections on and assessment of his or her teaching effectiveness and the teacher's plans for future instruction, including assessment. We asked the teacher to reflect on his or her reasons for choosing or designing the tasks used in the lesson and to comment on their effectiveness. Also, we asked the teachers whether they felt their students had achieved the learning goals identified before the lesson and how they might assess this later.

\section{Data analysis}

We used the lesson as the unit to analyze the cognitive levels of the learning goals for the lessons. In the preliminary coding of our data, we found it difficult to code into Anderson and Krathwohl's (2001) six levels of cognitive demand for learning goals with a high degree of reliability. We decided to modify the system, removing the applying level and inserting a level called Practicing, resulting in the following four levels of cognitive demand:

- Level 1: Remembering: retrieving, recognizing, and recalling relevant knowledge from long-term memory. An example from the teachers' interviews conducted for this study is: "Recall divisibility rules, order of operation and prime factorization."

- Level 2: Practicing: carrying out or using a procedure through executing, or implementing. An example from the teachers' interviews conducted for this study is: "Determine the area, base or height of a parallelogram, given the other two measurements. Use variables in a formula." 
- Level 3: Understanding: constructing meaning from oral, written, and graphic messages through interpreting, exemplifying, classifying, summarizing, inferring, comparing, and explaining. An example from the teachers' interviews conducted for this study is: "Understand the relationship between ratios and proportions."

- Level 4: Analyzing: breaking material into constituent parts, determining how the parts relate to one another and to an overall structure or purpose through differentiating, organizing, and attributing; making judgments based on criteria and standards through checking and critiquing; putting elements together to form a coherent or functional whole; reorganizing elements into a new pattern or structure through generating, planning, or producing. An example from the teachers' interviews conducted for this study is: "The primary learning goal in this lesson is for the students to be able to understand how to use the data from the graph to draw conclusions about the specific situations."

With these four levels, we were able to code the data with a high degree of reliability ( $90 \%$ agreement). In addition, by modifying the levels in this way we sought to capture a hierarchy of learning that commonly occurs in mathematics. Specifically, it is common for students to learn to apply mathematical procedures and formulas to situations without understanding why the procedure or formula gives a correct answer, or without being able to interpret what the answer means. Our test coding verified that the modified four-level model worked well to capture this pattern.

Thus, for our analysis of the teachers' planned learning goals, we coded each intended learning goal to determine whether its level of cognitive demand was (1) Remembering, (2) Practicing, (3) Understanding, or (4) Analyzing. Then, we compared the codes and identified the intended learning goal with the highest level of cognitive demand for each lesson. We assigned that highest level of cognitive demand to the lesson as a whole.

As it turned out, the majority of learning goals fell into the Practicing and Understanding categories for both the CMP and non-CMP groups. Thus, to facilitate further analysis we collapsed our four categories of cognitive demand into two levels of cognitive demand that more generally described the level at which thinking was called for in the classroom (Fernandez \& Cannon, 2005; Tate, 2006). Specifically, we collapsed the Remembering and Practicing levels into a single low level of cognitive demand, and the Understanding and Analyzing levels into a single high level of cognitive demand (Tate, 2006).

The codes for the other interview items such as anticipated student difficulties and reasons for choosing instructional tasks were developed by randomly selecting a group of ten interviews from the complete data set and using them to develop an initial set of rough codes. As a test of reliability, two researchers used the rough codes to code the interview data. Data codes that consistently yielded low agreement between the two coders were revised. Then the codes were tested again until the two coders reached high agreement on all the codes. For example, anticipated student difficulties were coded as: "Did not anticipate students having difficulties" or "Anticipated students having difficulties" (e.g., the lack of basic skills or may have trouble setting up proportions). Reasons for choosing instructional tasks were coded as: "Follow the book", "Meeting student learning needs", or "Others" (e.g., alignment to state/district testing schedule). Using the resulting coding scheme, the two researchers coded 20 interviews independently, and averaged $91 \%$ perfect agreement per interview.

\section{Results}

In presenting our results, we interweave findings based on the teachers' responses about their intentions for their lessons beforehand and their reflections about the lessons afterward. We begin by considering the learning 
goals, and then report on the teachers' anticipation of student difficulties and perceptions of student achievement. Finally, we consider teachers' rationales for choosing particular instructional tasks.

\section{Learning goals}

The cognitive levels of the intended learning goals for the lessons planned by the CMP and non-CMP teachers were significantly different $\left[\chi^{2}(3, n=569)=32.11, p<0.0001\right]$. As shown in Table 1 , very few CMP or non-CMP teachers planned lesson goals that were coded as Remembering. The learning goals for the majority of the lessons planned by both CMP and non-CMP teachers were categorized as Practicing or Understanding. Non-CMP teachers planned significantly more lessons with learning goals categorized as Practicing than CMP teachers $(z=4.50, p<0.0001)$, while CMP teachers more often planned learning goals that were categorized as Understanding $(z=2.53, p<0.05)$.

Table 1 Percentage distribution of the cognitive demand levels of the learning goals planned by CMP and nonCMP teachers

\begin{tabular}{|l|l|l|l|l|}
\hline & Low level & & High level & \\
\hline & Remembering & Practicing & Understanding & Analyzing \\
\hline $\mathrm{CMP}(n=301)$ & 2 & 34 & 53 & 11 \\
\hline Non-CMP $(n=268)$ & 3 & 52 & 43 & 2 \\
\hline
\end{tabular}

A total of $64 \%$ of the intended learning goals planned by the CMP teachers were at a high level of cognitive demand. That was 19 percentage points greater than the percent (45\%) of intended learning goals planned by the non-CMP teachers that were at a high level of cognitive demand $\left[\chi^{2}(1, n=569)=22.19, p<0.0001\right]$. These two results reveal that non-CMP teachers planned significantly fewer lessons having high-level learning goals, and accordingly, significantly more lessons having low-level learning goals than their CMP counterparts.

As stated above, the observers identified the learning goals that the textbooks and curriculum materials specified for each observed lesson. For example, the teacher's edition of CMP included the following learning goal for a lesson on solving linear equations: "to solve an equation of the form $y=m x+b$ symbolically." (Moving straight ahead (teacher's guide), 2002, p. 52r). We examined the degree to which the teachers' self-reported intended learning goals for each lesson aligned with these text-specified learning goals. In general, the non-CMP teachers were more likely than the CMP teachers to specify learning goals for the lesson that completely matched the goals listed in the curriculum materials $\left[\chi^{2}(2, n=575)=62.17, p<0.0001\right]$. Indeed, $76 \%$ of the non-CMP lessons had intended learning goals that completely matched the textbook goals, whereas only $45 \%$ of the CMP lessons had intended learning goals that completely matched the textbook goals. In just over half of the CMP lessons (51\%), the intended learning goals only partially matched those from the text.

In order to gain an additional perspective on how the teachers implemented their lessons, we considered the learning goals that the observers identified as having actually been implemented in the classroom. Recall that the observer's identification was based on his/her observation of the lesson, not on what the book said the learning goals ought to be or on what the teacher said they were going to be during the pre-lesson interview. These observer-identified implemented learning goals were not always the same as the teachers' self-reported intended learning goals. Table 2 affords comparisons between the learning goals planned by teachers (the intended learning goals) and the learning goals perceived by observers based on their observations of the lessons (the implemented learning goals). For CMP lessons, the percentage of implemented high-level lessons (lessons that implemented high-level cognitive demand learning goals) was significantly smaller than the 
percentage of intended high-level lessons ( 54 vs. $64 \% ; z=2.47, p<0.05$ ). With regard to the non-CMP lessons, there was no significant difference between the percentages of implemented and intended high-level lessons ( 39 vs. $45 \% ; z=1.24, p=0.21$ ). However, the percentage of implemented high-level CMP lessons remained significantly greater than the percentage of implemented high-level non-CMP lessons (54 vs.

$39 \% ; z=3.62, p<0.001)$.

Table 2 Percentages of CMP and non-CMP intended and implemented learning goals categorized by cognitive demand

\begin{tabular}{|l|l|l|l|l|}
\hline & Low level & & High level & \\
\hline & Remembering & Practicing & Understanding & Analyzing \\
\hline CMP* $^{*}$ & & & & \\
\hline Intended $^{\text {a }}(n=301)$ & 2 & 34 & 53 & 11 \\
\hline Implemented $^{\text {b }}(n=304)$ & 2 & 43 & 47 & 7 \\
\hline Non-CMP & & & & \\
\hline Intended $^{\text {a }}(n=268)$ & 3 & 52 & 43 & 2 \\
\hline Implemented $^{\text {b }}(n=271)$ & 1 & 59 & 39 & 0 \\
\hline
\end{tabular}

$* p<0.05$

Intended: teacher-planned learning goals

bImplemented: observer-perceived learning goals

\section{Teachers' anticipation of students' difficulties and their perceptions of students' achievement of learning goals}

\section{Teachers' anticipation of students' difficulties}

We asked the teachers whether they anticipated that their students would have any difficulties with the mathematics of the lesson. For approximately $30 \%$ of the lessons in both groups, teachers anticipated their students would have no problems with the mathematics. If the teachers did express an anticipation of student difficulty with the mathematics, we asked them to explain the nature of the anticipated difficulties. We coded their responses into two categories: general (e.g., "Yes, because some are very far behind.") or specific: (e.g., "Some will have trouble solving for $b$ or $h$ in $\left.A=b^{*} h^{\prime}\right)$. The percentages of anticipated difficulties in each category were similar for the CMP and non-CMP teachers (13\% general; $55 \%$ specific). A Chi-square test showed there was no significant difference between CMP and non-CMP teachers' anticipation of the students' difficulties $\left[\chi^{2}(2, n=567)=1.58, p=0.45\right]$.

\section{Teachers' perceptions of students' achievement of learning goals}

There were significant differences between the CMP and non-CMP teachers' perceptions of the extent to which their students achieved the learning goals of the lessons $\left[\chi^{2}(3, n=570)=28.73, p<0.0001\right]$ (see Table 3). Many more non-CMP teachers thought their students partially or completely achieved the goals of the lesson than CMP teachers (84 vs. $66 \% ; z=4.93, p<0.0001$ ) (these percentages are the sums of the respective non-CMP and CMP percentages in the "Partially Achieved" and "Completely Achieved" columns in Table 3). Accordingly, more CMP teachers than non-CMP teachers indicated that their students did not achieve the goals ( 25 vs.

$14 \% ; z=3.51, p<0.001)$.

Table 3 Percentage distribution of CMP and non-CMP lessons in which teachers perceived that students achieved the learning goals regardless of the levels of learning goals

\begin{tabular}{|l|l|l|l|} 
Not achieved & Partially achieved & Completely achieved & Not sure \\
\hline
\end{tabular}




\begin{tabular}{|l|l|l|l|l|}
\hline $\operatorname{CMP}(n=297)$ & 25 & 32 & 34 & 8 \\
\hline $\operatorname{Non}-\mathrm{CMP}(n=273)$ & 14 & 34 & 50 & 2 \\
\hline
\end{tabular}

Recall that there was a higher percentage of CMP lessons than non-CMP lessons for which teachers intended high-cognitive-level learning goals. Considering these high level lessons only, the percentage of CMP lessons for which the teachers reported that students partially or completely reached the learning goals (hereafter referred to as successful lessons) was not significantly different from the percentage of successful non-CMP lessons (46 vs. $38 \% ; z=1.89, p=0.06$ ). Also as stated above, there was a higher percentage of non-CMP than CMP lessons for which teachers intended low-cognitive-level learning goals. The percentage of intended low-level non-CMP lessons that teachers viewed as successful was significantly greater than the percentage of successful intended low-level CMP lessons (47 vs. $21 \%$; $z=6.52, p<0.001$ ).

As we noted above, the cognitive levels of the learning goals that the observers perceived as actually being implemented during the lessons were often different than the cognitive levels of the learning goals that were intended by the teachers before the lessons began. It was possible that the teachers' perceptions of whether the students had achieved the learning goals may have been based on these implemented learning goals rather than on the intended learning goals. Therefore, we also analyzed the relationship between the level of the implemented learning goals and the teachers' perception of success (i.e., perceiving that students achieved the learning goals). The results of this analysis were generally in accord with the previous analysis. Overall, there was a significantly greater percentage of successful non-CMP lessons than successful CMP lessons (84 vs.

$66 \% ; z=4.99, p<0.001$ ). The percentage of successful high-level CMP lessons was not significantly different from the percentage of successful high-level non-CMP lessons (38 vs. $34 \% ; z=0.92, p=0.36$ ), and the percentage of successful low-level non-CMP lessons was significantly higher than the percentage of successful low-level CMP lessons (50 vs. $28 \% ; z=5.36, p<0.001$ ).

\section{Anticipated difficulties versus achieved learning goal}

We separated the lessons into two groups: those for which the teachers anticipated that students would have difficulties with the lesson's mathematics and those for which teachers anticipated no such difficulties (see Table 4). We found that the teachers' anticipation of student difficulties was significantly related to the extent to which the learning goals were achieved $\left[\chi^{2}(3, n=558)=12.89, p<0.01\right]$ (see Table 4). That is, the teachers perceived that students failed to achieve the learning goals in significantly more lessons in which they had anticipated difficulties than in lessons in which they had not, (22 vs. $13 \% ; z=2.48, p<0.05$ ).

Table 4 Percentage distribution of students' level of learning goal achievement perceived by teachers who did and did not anticipate students having difficulties

\begin{tabular}{|l|l|l|l|l|}
\hline & $\begin{array}{l}\text { Not } \\
\text { achieved }\end{array}$ & $\begin{array}{l}\text { Partially } \\
\text { achieved }\end{array}$ & $\begin{array}{l}\text { Completely } \\
\text { achieved }\end{array}$ & $\begin{array}{l}\text { Not } \\
\text { sure }\end{array}$ \\
\hline $\begin{array}{l}\text { Anticipated students having difficulties } \\
(n=388)\end{array}$ & 22 & 34 & 40 & 4 \\
\hline $\begin{array}{l}\text { Did not anticipate students having } \\
\text { difficulties }(n=170)\end{array}$ & 13 & 31 & 46 & 9 \\
\hline
\end{tabular}

When separating only the CMP lessons based on anticipated student difficulty with the mathematics (see Table 5), we again found that the teachers' anticipation (or not) of student difficulty was significantly related to the extent to which teachers later felt that students achieved the learning goals 
$\left[\chi^{2}(3, n=293)=15.45, p<0.01\right]$. However when looking at the same groupings for the non-CMP lessons, we found no such relationship $(p=0.11)$.

Table 5 Percentage distribution of students' level of learning goal achievement perceived by CMP and nonCMP teachers who did and did not anticipate students having difficulties

\begin{tabular}{|c|c|c|c|c|}
\hline & $\begin{array}{l}\text { Anticipated students } \\
\text { having difficulties }\end{array}$ & & $\begin{array}{l}\text { Did not anticipate students } \\
\text { having difficulties }\end{array}$ & \\
\hline & $\mathrm{CMP}(n=211)$ & $\begin{array}{l}\text { Non-CMP } \\
(n=177)\end{array}$ & CMP $(n=82)$ & $\begin{array}{l}\text { Non-CMP } \\
(n=88)\end{array}$ \\
\hline Not achieved & 27 & 16 & 17 & 9 \\
\hline $\begin{array}{l}\text { Partially } \\
\text { achieved }\end{array}$ & 32 & 36 & 33 & 30 \\
\hline $\begin{array}{l}\text { Completely } \\
\text { achieved }\end{array}$ & 36 & 45 & 32 & 60 \\
\hline Not sure & 5 & 3 & 18 & 1 \\
\hline
\end{tabular}

\section{Instructional tasks}

\section{Teachers' reasons for choosing instructional tasks}

In the post-lesson interviews, the teachers were asked to reflect on their reasons for choosing the instructional tasks that they implemented in their lessons. The vast majority of the teachers provided very brief responses consisting of a single sentence or a few phrases, but their responses were still quite informative. The responses largely fell into one of two categories. Many teachers noted that they were following the guidance of the textbook in preparing their lesson. For example, one teacher stated that "I used the examples in the order they were done in the book." Other teachers felt that they chose their instructional tasks in order to respond to student thinking ("Took my cue from what the students were asking or interested in.") or to meet particular student learning needs ("They needed more practice on equivalent fractions and on placing numbers on the number line."). No teacher included both types of reasons in their response. A very small percentage of the teachers provided reasons not in one of these two categories, such as preparing for the state test. The profile of reasons given by the CMP teachers was significantly different than that of the non-CMP teachers $\left[\chi^{2}(2, n=577)=27.46, p<0.0001\right]$ (see Table 6).

Table 6 Percentage distribution of CMP and non-CMP teachers' reasons for using particular instructional tasks to design lessons

\begin{tabular}{|l|l|l|l|}
\hline & Following book & Considering student learning needs & Others \\
\hline $\mathrm{CMP}(n=304)$ & 71 & 24 & 5 \\
\hline Non-CMP $(n=273)$ & 50 & 41 & 9 \\
\hline
\end{tabular}

The percentage of the CMP lessons in which teachers cited "following the textbook" as the reason for using the instructional tasks was significantly greater than that of the non-CMP lessons (71 vs. $50 \% ; z=5.17, p<0.0001$ ). Correspondingly, the percentage of the non-CMP lessons in which teachers cited "considering student learning needs" as their reason for choosing examples or problems was significantly greater than that of the CMP lessons 
(41 vs. $24 \% ; z=4.28, p<0.0001$ ). Thus, in a larger percentage of CMP lessons than non-CMP lessons, teachers chose their instructional tasks by following the textbook, but in a larger percentage of non-CMP lessons than CMP lessons teachers chose their instructional tasks by considering student learning needs.

\section{Reasons for using instructional tasks versus achieved learning goal}

When we aggregated the CMP and non-CMP lessons, we found that the teachers' reasons for choosing particular instructional tasks were significantly related to the levels at which they later felt their students achieved the lessons' learning goals $\left[\chi^{2}(6, n=569)=24.34, p<0.001\right]$. This difference appears to be the result of a significantly higher percentage of the "following the textbook" lessons failing to achieve their learning goals than the "considering student learning needs" lessons ( 25 vs. $12 \% ; z=3.43, p<0.001$ ).

When we analyzed the CMP lessons separately, the same relationship persisted ( $p<0.001$, Fisher's exact test) (see Table 7). However, there was no statistically significant relationship between the reasons the teachers chose the instructional tasks and their perception of the learning goals being reached in the non-CMP lessons ( $p=0.76$, Fisher's exact test). Again, the difference for the CMP classrooms appears to be attributable to the percentage of "following the book" lessons that failed to achieve their learning goals being significantly greater than the percentage of "considering student learning needs" lessons that failed to do so (30 vs.

$15 \% ; z=2.59, p<0.01$ ). For the non-CMP lessons, the percentage of "following the textbook" lessons that failed to achieve their learning goals was higher, but not significantly higher, than the percentage of "considering student learning needs" lessons that failed to do so (17 vs. $11 \% ; z=1.40, p=0.16$ ).

Table 7 Percentage distribution of students' level of learning goal achievement perceived by CMP and nonCMP teachers with different reasons for choosing particular instructional tasks

\begin{tabular}{|c|c|c|c|c|c|c|c|c|}
\hline & $\begin{array}{l}\text { Not } \\
\text { achieved }\end{array}$ & & $\begin{array}{l}\text { Partially } \\
\text { achieved }\end{array}$ & & $\begin{array}{l}\text { Completely } \\
\text { achieved }\end{array}$ & & $\begin{array}{l}\text { Not } \\
\text { sure }\end{array}$ & \\
\hline & CMP & $\begin{array}{l}\text { Non- } \\
\text { CMP }\end{array}$ & CMP & $\begin{array}{l}\text { Non- } \\
\text { CMP }\end{array}$ & CMP & $\begin{array}{l}\text { Non- } \\
\text { CMP }\end{array}$ & CMP & $\begin{array}{l}\text { Non- } \\
\text { CMP }\end{array}$ \\
\hline \multicolumn{9}{|l|}{ Following the book } \\
\hline$n=208(\mathrm{CMP})$ & 30 & 17 & 31 & 31 & 34 & 50 & 5 & 2 \\
\hline \multicolumn{9}{|l|}{$n=136$ (non-CMP) } \\
\hline \multicolumn{9}{|l|}{$\begin{array}{l}\text { Considering } \\
\text { student learning } \\
\text { needs }\end{array}$} \\
\hline$n=74(\mathrm{CMP})$ & 15 & 11 & 39 & 37 & 35 & 50 & 11 & 3 \\
\hline \multicolumn{9}{|l|}{$n=112$ (non-CMP) } \\
\hline \multicolumn{9}{|l|}{ Other reasons } \\
\hline$n=14(\mathrm{CMP})$ & 7 & 8 & 14 & 40 & 36 & 52 & 43 & 0 \\
\hline$n=25$ (non-CMP) & & & & & & & & \\
\hline
\end{tabular}

\section{Discussion}

In this study, we have explored teachers' intentions for and reflections on their instruction in order to examine the connections between that instruction and the textbooks and curriculum materials the teachers use. We will now discuss our findings concerning the relationship between curriculum materials and teachers' instruction in the context of learning goals, instructional tasks, and perceptions of student learning and difficulty.

As we have reported elsewhere, the CMP textbooks provide significantly more high cognitive level tasks for teachers to implement than the non-CMP textbooks in our study (Cai et al., 2010; Nie et al., 2009). One might 
reasonably expect, then, that teachers who base lessons on CMP textbooks would more often include high-level learning goals than teachers using non-CMP textbooks. Indeed, this was the case for the CMP teachers in this study. These findings are consistent with our classification by cognitive demand of the $305 \mathrm{CMP}$ and 274 nonCMP lessons that we observed in the sixth, seventh, and eighth grade classrooms of the LieCal Project (Cai et al., 2009). We found that significantly more CMP lessons than non-CMP lessons were implemented at a high level of cognitive demand (at least one instructional task at either the procedures with connections or the doing mathematics level).

However, it would be naive to claim a straightforward relationship between the nature of the learning goals and instructional tasks provided in a textbook and their implementation as lessons taught in the classroom. Indeed, when we compared the teachers' intended learning goals to their implemented learning goals as perceived by the observers, the percentage of CMP lessons that were actually implemented with high-level cognitive demand learning goals was lower than the percentage of lessons that had been planned with high-level cognitive demand goals. Thus, while the cognitive level of the teachers' intended learning goals does appear to reflect the emphases of their respective textbooks, the teachers' implementations of the lessons seem to reduce the degree of difference. This phenomenon may reflect the confirmed difficulty of maintaining a high level of cognitive demand for instructional tasks in classrooms (Stein et al., 1996). This suggests that, with respect to learning goals, the textbook emphasis may shape the goals of instruction, but this influence is mediated by the realities of implementation. In addition, although teachers may make adaptations to their curriculum plans in the moment, which are further transformed as the teachers implement them in the classroom (Remillard, 1999), it is curious that the non-CMP teachers' stated learning goals were more often in alignment with the learning goals specified in their curriculum materials than was the case for the CMP teachers. This lower degree of coherence between the textbook and the CMP teachers' intentions is notable, though it is not clear whether it is rooted in issues with teacher understanding of the text and its learning goals, incompatibilities between Standards-based texts and traditional practices, or some other set of causes. This finding does suggest a locus for future analyses to better understand the nature of difficulties with implementation of CMP curriculum materials.

We also found that the CMP teachers were more likely than the non-CMP teachers to follow the guidance of their textbooks in designing and selecting instructional tasks for a lesson. In other words, CMP teachers were more willing to choose and implement instructional tasks from their textbook than non-CMP teachers. This finding echoes that of Lloyd (1999) in her case study of high school teachers implementing Standards-based curriculum materials that the teachers tended not to alter the problems they used from their curriculum. It also reinforces the findings reported in Moyer et al. (2011) that the CMP teachers were more likely to have a conceptual emphasis in their lessons and non-CMP teachers were more likely to have a procedural emphasis. Given that CMP lessons explicitly focus on conceptual development, it is reasonable to expect that if the CMP teachers are more likely to follow their textbook, then their instruction will have a conceptual emphasis.

However it should be noted that in the present study, the CMP teachers who chose instructional tasks by following the textbook were more likely to consider that their students failed to achieve the learning goals than CMP teachers who chose tasks based on considerations of student thinking. This pattern did not hold for the non-CMP teachers. Given that the non-CMP teachers were more likely to specify learning goals that matched those in their textbooks, it may be that this difference in perceived outcomes reflects a disjunction between the CMP teachers' intended learning goals and the learning goals that the CMP instructional tasks were designed to support. If the CMP teachers more often followed the textbook in selecting instructional tasks, but also set learning goals for their students that were not aligned with those tasks, it would seem reasonable that they would more frequently perceive that their students were not meeting the learning goals. A future analysis is needed to test this hypothesis. 
Finally, with regard to the teachers' perceptions of their students' achievement, we found that non-CMP lessons were, on the whole, more likely to be viewed as successful by the teacher than were CMP lessons. For CMP and non-CMP lessons with high-level learning goals, student achievement of the learning goals was perceived comparably by the respective teachers. However, for lessons with low-level learning goals, non-CMP teachers were more likely to consider that students had achieved the learning goals. That is to say, this study did not reveal any significant difference between the use of CMP and non-CMP curriculum materials with respect to the teachers' perceptions of their students' achievement of high-level learning goals. However, this study did show that the non-CMP curriculum materials were associated with a greater positive relationship than the CMP curriculum materials on teachers' perceptions of their students' achievement of low-level learning goals. As might be expected, when teachers anticipated that students would have difficulty with the mathematics in a lesson, that lesson was less likely to be successful in the eyes of the teacher.

The disconnects among the CMP curriculum's learning goals, the CMP teachers' intended learning goals, the CMP teachers' implemented learning goals, and the CMP teachers' perception of their students' achievement may have taken its toll. In the 2007-2008 school year, teachers in 11 of the 14 schools that used the CMP curriculum during our project chose to discontinue their use of the CMP curriculum in favor of a more traditional text.

In our investigation of the interplay between textbooks and instruction, we have focused on learning goals, instructional tasks, and teachers' anticipation of students' difficulties and their perceptions of students' achievement of learning goals, all of which are aspects of teachers' intentions and reflections that have proven fruitful in comparing the role of the CMP and non-CMP curricula in our project. Future research should consider other aspects of teachers' intentions and reflections that may shed a broader light on the role of textbooks and curriculum materials in teachers' crafting of instructional experiences. We feel that much can yet be learned about the implementation and support requirements of innovative curricula and textbooks by examining the ways in which teachers think about, plan, and assess their own instruction.

\section{References}

Anderson, L. W., \& Krathwohl, D. R. (Eds.). (2001). A taxonomy for learning, teaching, and assessing: A revision of Bloom's taxonomy of educational objectives. New York: Addison Wesley Longman.

Bolhuis, S. (2003). Towards process-oriented teaching for self-directed lifelong learning: A multidimensional perspective. Learning and Instruction, 13, 327-347.

Butts, D. P., Koballa, T., Anderson, M., \& Butts, D. P. (1993). Relationship between teacher intentions and their classroom use of Superscience. Journal of Science Education and Technology, 2, 349-357.

Cai, J., \& Lester, F. K. (2005). Solution representations and pedagogical representations in Chinese and U.S. classrooms. Journal of Mathematical Behavior, 24, 221-237.

Cai, J., Moyer, J., Nie, B., \& Wang, N. (2009). Learning mathematics from classroom instruction using Standardsbased and traditional curricula: An analysis of instructional tasks. In S. L. Swars, D. W. Stinson, \& S. Lemons-Smith (Eds.), Proceedings of the 31st annual meeting of the North American Chapter of the International Group for the Psychology of Mathematics Education (Vol. 5, pp. 692-699). Atlanta: Georgia State University.

Cai, J., Ni, Y., \& Lester, F. K. (2011a). Curricular effect on the teaching and learning of mathematics: Findings from two longitudinal studies in China and the United States. International Journal of Educational Research, 50, 63-64.

Cai, J., Nie, B., \& Moyer, J. (2010). The teaching of equation solving: Approaches in Standards-based and traditional curricula in the United States. Pedagogies: An International Journal, 5, 170-186.

Cai, J., \& Wang, T. (2010). Conceptions of effective mathematics teaching within a cultural context: Perspectives of teachers from China and the United States. Journal of Mathematics Teacher Education, 13, 265-287. 
Cai, J., Wang, N., Moyer, J. C., Wang, C., \& Nie, B. (2011b). Longitudinal investigation of the curriculum effect: An analysis of student learning outcomes from the LieCal Project. International Journal of Educational Research, 50, 117-136.

Carpenter, T. P., Fennema, E., Peterson, P. L., Chiang, C. P., \& Loef, M. (1989). Using knowledge of children's mathematics thinking in classroom teaching: An experimental study. American Educational Research Journal, 26, 499-531.

Cazden, C. B. (1986). Classroom discourse. In M. C. Wittrock (Ed.), Handbook of research on teaching (3rd ed., pp. 432-463). New York: Macmillan.

Cobb, P., \& Bauersfeld, H. (Eds.). (1995). The emergence of mathematical meaning-interaction in classroom cultures. Hillsdale, NJ: Lawrence Erlbaum.

Cooney, T. J., Shealy, B. E., \& Arvold, B. (1998). Conceptualizing belief structures of preservice secondary mathematics teachers. Journal for Research in Mathematics Education, 29, 306-333.

Doyle, W. (1983). Academic work. Review of Educational Research, 53, 159-199.

Doyle, W. (1988). Work in mathematics classes: The context of students' thinking during instruction. Educational Psychologist, 23, 167-180.

Fennema, E., \& Franke, M. L. (1992). Teachers' knowledge and its impact. In D. A. Grouws (Ed.), Handbook of research on mathematics teaching and learning: A project of the National Council of Teachers of Mathematics (pp. 147-164). New York: Macmillan.

Fernandez, C., \& Cannon, J. (2005). What Japanese and U.S. teachers think about when constructing mathematics lessons: A preliminary investigation. Elementary School Journal, 105, 481-498.

Forman, E. A., \& Cazden, C. B. (1985). Exploring Vygotskian perspectives in education: The cognitive value of peer interaction. In J. V. Wertsch (Ed.), Culture, communication and cognition: Vygotskian perspectives (pp. 323-347). New York: Cambridge University Press.

Gross, S., \& Merchlinsky, S. (2002). Evaluation of the Singapore Math Pilot Program: Year I report of findings. MD: Montgomery County Public Schools Office of Shared Accountability.

Hatton, N., \& Smith, D. (1995). Reflection in teacher education: Towards definition and implementation. Teaching and Teacher Education, 11, 33-49.

Hiebert, J., Carpenter, T. P., Fennema, E., Fuson, K. C., Wearne, D., Murray, H., Olivier, A., \& Human, P. (1997). Making sense: Teaching and learning mathematics with understanding. Portsmouth, NH: Heinemann.

Hiebert, J., Gallimore, R., Garnier, H., Givvin, K. B., Hollingsworth, H., Jacobs, J., Chui, A. M., Wearne, D., Smith, M., Kersting, N., Manaster, A., Tseng, E., Etterbeek, W., Manaster, C., Gonzales, P., \& Stigler, J. (2003). Teaching mathematics in seven countries: Results from the TIMSS 1999 Video Study. Washington, DC: National Center for Education Statistics, U.S. Department of Education.

Hiebert, J., \& Stigler, J. W. (2000). A proposal for improving classroom teaching: Lessons from the TIMSS video study. Elementary School Journal, 101, 3-20.

Hiebert, J., \& Wearne, D. (1993). Instructional tasks, classroom discourse, and students' learning in second-grade arithmetic. American Educational Research Journal, 30, 393-425.

Hill, H., Ball, D., \& Schilling, S. (2008). Unpacking pedagogical content knowledge: Conceptualizing and measuring teachers' topic-specific knowledge of students. Journal for Research in Mathematics Education, 39, 372400.

Jackson, P. W. (1990). Life in classrooms. New York: Teachers College Press.

Lampert, M. (1990). When the problem is not the question and the solution is not the answer: Mathematical knowing and teaching. American Educational Research Journal, 27, 29-63.

Lloyd, G. M. (1999). Two teachers' conceptions of a reform curriculum: Implications for mathematics teacher development. Journal of Mathematics Teacher Education, 2, 227-252.

McDuffie, A. R., \& Mather, M. (2012). Middle school mathematics teachers' use of curricular reasoning in a collaborative professional development project. In J. T. Remillard, B. A. Herbel-Eisenmann, \& G. M. Lloyd (Eds.), Mathematics teachers at work: Connecting curriculum materials and classroom instruction (pp. 302-320). New York: Routledge. 
Moyer, J. C., Cai, J., \& Laughlin, C. (2009a). High quality coaching using the LieCal observation instrument. Journal of Mathematics Education Leadership, 11(1), 12-20.

Moyer, J. C., Cai, J., Laughlin, C., \& Wang, N. (2009b). The effect of curriculum type on middle grades instruction. In S. L. Swars, D. W. Stinson, \& S. Lemons-Smith (Eds.), Proceedings of the 31st annual meeting of the North American Chapter of the International Group for the Psychology of Mathematics Education (Vol. 5, pp. 201-209). Atlanta, GA: Georgia State University.

Moyer, J. C., Cai, J., Wang, N., \& Nie, B. (2011). Impact of curriculum reform: Evidence of change in classroom practice in the United States. International Journal of Educational Research, 50, 87-99.

Nie, B., Cai, J., \& Moyer, J. C. (2009). How a standards-based mathematics curriculum differs from a traditional curriculum: with a focus on intended treatments of the ideas of variable. ZDM - The International Journal on Mathematics Education, 41, 777-792.

Perry, M., VanderStoep, S. W., \& Yu, S. L. (1993). Asking questions in first-grade mathematics classes: Potential influences on mathematical thought. Journal of Educational Psychology, 85, 31-40.

RAND Mathematics Study Panel. (2003). Mathematical proficiency for all students: Toward a strategic research and development program in mathematics education (MR-1643-OERI). Santa Monica, CA: RAND.

Remillard, J. T. (1999). Curriculum materials in mathematics education reform: A framework for examining teachers' curriculum development. Curriculum Inquiry, 29, 315-342.

Remillard, J. T. (2005). Examining key concepts in research on teachers' use of mathematics curricula. Review of Educational Research, 75, 211-246.

Shulman, L. S. (1986). Those who understand: Knowledge growth in teaching. Educational Researcher, 15(2), 414.

Silver, E. A., Ghousseini, H., Charalambous, C. Y., \& Mills, V. (2012). Exploring the curriculum implementation plateau: An instructional perspective. In J. T. Remillard, B. A. Herbel-Eisenmann, \& G. M. Lloyd (Eds.), Mathematics teachers at work: Connecting curriculum materials and classroom instruction (pp. 245-265). New York: Routledge.

Spillane, J. P. (2000). A fifth-grade teacher's reconstruction of mathematics and literacy teaching: Exploring interactions among identity, learning, and subject matter. Elementary School Journal, 100, 307-330.

Spillane, J. P., \& Zeuli, J. S. (1999). Reform and teaching: Exploring patterns of practice in the context of national and state mathematics reform. Educational Evaluation and Policy Analysis, 21, 1-27.

Stein, M. K., Grover, B. W., \& Henningsen, M. (1996). Building student capacity for mathematical thinking and reasoning: An analysis of mathematical tasks used in reform classrooms. American Educational Research Journal, 33, 455-488.

Stein, M. K., \& Lane, S. (1996). Instructional tasks and the development of student capacity to think and reason: An analysis of the relationship between teaching and learning in a reform mathematics project. Educational Research and Evaluation, 2, 50-80.

Stein, M. K., \& Smith, M. S. (1998). Mathematical tasks as a framework for reflection: From research to practice. Mathematics Teaching in the Middle School, 3, 268-275.

Tate, W. F. [issue researcher] (2006). Do the math: Cognitive demand makes a difference. Research Points, 4(2), 1-4.

Thompson, A. G. (1992). Teachers' beliefs and conceptions: A synthesis of the research. In D. A. Grouws (Ed.), Handbook of research on mathematics teaching and learning (pp. 127-146). NY: Macmillan.

West, L., \& Staub. F. C. (2003). Content-focused coaching SM : Transforming mathematics lessons. Portsmouth, $\mathrm{NH}$ : Heinemann \& Pittsburgh: University of Pittsburgh.

\section{Acknowledgments}

The research reported here is supported by Grants from the National Science Foundation (ESI-0454739 and DRL1008536). Any opinions expressed herein are those of the authors and do not necessarily represent the views of the National Science Foundation. 


\section{Appendices}

\section{Appendix A: Teacher interview questions}

Before the lesson: pre-observation conversation with the teacher

1. What is the main topic of the lesson?

2. What are the primary learning goals or objectives in this lesson?

3. Where is the lesson situated within the unit? How will the present lesson connect to previous or subsequent lessons? What do you assume your students already know?

4. Do you anticipate any potential difficulties in delivering the lesson? If so, how do you plan to handle them if they arise?

5. Do you anticipate any difficulties the students will have with the mathematics in the lesson?

6. Have you taught this lesson before?

7. What kind of questions do you plan to ask on a quiz or exam based on the contents of this lesson?

After the lesson: post-observation interview with the teacher

1. Looking back, what made you decide to choose the particular examples/problems you used?

2. Now that you have taught the lesson, please reflect on the effectiveness of using these examples/problems in this lesson.

3. For this lesson, the main goal you had for your students was: (see question 2 of the preobservation interview). Do you think your students reached the goal?

4. What will the next lesson look like?

5. What kind of questions will you ask on a quiz or exam based on the contents of this lesson?

\section{Appendix B: Observed goals and curricular goals}

\begin{tabular}{l} 
8. What were the primary learning goals or objectives of the lesson (from the observer's perspective)? \\
9. What are the primary goals or objectives of this lesson, as specified in the curriculum \\
materials? \\
a. \\
b. \\
c. \\
d. \\
e. \\
f. \\
\hline 0. To what extent did the teacher attempt to facilitate students' achievement of the primary \\
goals or objectives of the lesson, as specified in the curriculum materials? Record a, b, c, d, \\
e, and f in the appropriate spaces below.
\end{tabular}

\begin{tabular}{|l|l|l|l|l|}
\hline 1 & 2 & 3 & 4 & 5 \\
\hline No Attempt & & Partial Attempt & & Thorough Attempt \\
\hline
\end{tabular}


8. What were the primary learning goals or objectives of the lesson (from the observer's perspective)?

9. What are the primary goals or objectives of this lesson, as specified in the curriculum materials?

a.

b.

c.

d.

e.

f.

10. To what extent did the teacher attempt to facilitate students' achievement of the primary goals or objectives of the lesson, as specified in the curriculum materials? Record a, b, c, d, $\mathrm{e}$, and $\mathrm{f}$ in the appropriate spaces below.

\begin{tabular}{|c|c|c|c|c|}
\hline $\mathbf{1}$ & $\mathbf{2}$ & $\mathbf{3}$ & $\mathbf{4}$ & $\mathbf{5}$ \\
\hline No Attempt & & Partial Attempt & & Thorough Attempt \\
& & & & \\
\hline
\end{tabular}

Rights and permissions

$\underline{\text { Reprints and Permissions }}$

About this article

Cite this article

Nie, B., Freedman, T., Hwang, S. et al. An investigation of teachers' intentions and reflections about using Standards-based and traditional textbooks in the classroom. ZDM Mathematics Education 45, 699-711 (2013). https://doi.org/10.1007/s11858-013-0493-7

Download citation 
- Accepted07 February 2013

- Published24 February 2013

- Issue DateSeptember 2013

- DOlhttps://doi.org/10.1007/s11858-013-0493-7

Share this article

Anyone you share the following link with will be able to read this content:

Get shareable link

Provided by the Springer Nature Sharedlt content-sharing initiative

Keywords

- Textbooks

- Curriculum reform

- Connected Mathematics Program

- Instructional tasks

- Teachers' intentions and reflections

- Learning goals

- Cognitive demand

- LieCal Project 